\title{
Los objetos del pasado y la enseñanza de la historia: la experiencia de El Museo Móvil
}

\section{Objects of the past and the teaching of history: the experience of $\mathrm{El}$ Museo Móvil (The traveling museum)}

\section{Medina Suárez, Víctor; Cobá Noh, Lorgio}

\section{Víctor Medina Suárez}

victor.medina@correo.uady.mx

Universidad Autónoma de Yucatán, México

Lorgio Cobá Noh lorgio.coba@correo.uady.mx Universidad Autónoma de Yucatán, México

Clio \& Asociados. La historia enseñada Universidad Nacional del Litoral, Argentina

ISSN: 2362-3063

Periodicidad: Semestral

núm. 33, 2021

clio@fhuc.unl.edu.ar

Recepción: 11 Agosto 2021

Aprobación: 05 Noviembre 2021

URL: https://doi.org/10.14409/cya.v0i33.10541

\section{c) (i) (2)}

Esta obra está bajo una Licencia Creative Commons AtribuciónNoComercial-CompartirIgual 4.0 Internacional.
Resumen: El presente trabajo explica la relevancia de los objetos del pasado, de origen doméstico, como materiales estratégicos para la reflexión pretérita y como alternativa a la crisis que enfrenta la enseñanza de la historia de carácter nacionalista. Nuestro objetivo es reflexionar sobre una experiencia didáctica a través del programa piloto titulado El Museo Móvil, que ha sido llevado a diversas escuelas secundarias y preparatorias del Estado de Yucatán, en México. Este ejercicio nos ha demostrado que el empleo de la didáctica del objeto que incorpora materiales con determinada carga simbólica y discursiva de carácter local y regional tiene potencial para articular, con mucho éxito, el proceso de enseñanzaaprendizaje que facilita asumir el pensamiento histórico, en su dimensión de consciencia histórica, que contribuye a formar una ciudadanía crítica y reflexiva.

Palabras clave: didáctica del objeto, identidad, patrimonio, pensamiento histórico, historia local.

\begin{abstract}
The present work explains the relevance of objects from the past, of domestic origin, as strategic materials for past reflection and as an alternative to the crisis faced by the teaching of history of a nationalist nature. Our objective is to reflect on a didactic experience through the pilot program entitled El Museo Móvil, which has been taken to various secondary and preparatory schools in the State of Yucatan, in Mexico. This exercise has shown us that the use of object didactics that incorporates materials with a certain symbolic and discursive load of a local and regional character has the potential to articulate, with great success, the teaching-learning process that facilitates assuming historical thought, in its dimension of historical consciousness, which contributes to forming a critical and reflective citizenship.
\end{abstract}

Keywords: didactics of the object, identity, heritage, historical thought, local history.

\section{Introducción}

Este documento tiene como objetivo presentar una experiencia didáctica de la enseñanza de la historia basada en objetos del pasado de origen doméstico, algunos de ellos dignas piezas para ser consideradas Patrimonio Cultural 
Material. Proponemos que este tipo de artefactos pueden ser muy útiles en la enseñanza de la historia y para fomentar las identidades familiares, locales e incluso nacionales. Para demostrarlo de forma concreta traeremos a colación el proyecto titulado El Museo Móvil que se ha presentado en 83 grupos de diversas escuelas secundarias, preparatorias e incluso en Organizaciones No Gubernamentales (ONGs) y ayuntamientos de la península de Yucatán, llegando a más de 2500 personas, en su mayoría adolescentes y jóvenes cursando educación media básica. Este esfuerzo se encuentra organizado bajo el auspicio de la Facultad de Ciencias Antropológicas de la Universidad Autónoma de Yucatán, e incluso sirve como un escenario real de aprendizaje para los alumnos de la Licenciatura en Historia que a él se suman, por la experiencia que obtienen en cuanto ejercicio de didáctica de la historia basada en objetos del pasado.

Desde hace algunas décadas se viene consolidando en la Licenciatura en Historia de la Universidad Autónoma de Yucatán una línea de investigación que apunta a transformar la forma de enseñar la Historia en las aulas con el objetivo de contribuir aportando egresados con conocimientos basados en la investigación y en la didáctica para ir supliendo a muchas personas que enseñaban historia sin la formación adecuada, con conocimiento básicos que hacían de la materia una cuestión tediosa, de preguntas y respuestas preconcebidas, anecdótica o de simples curiosidades que conducían a la historia de bronce o de los grandes héroes. Ante este panorama, la formación de historiadores profesionales con conocimientos más profundos en la materia se convertía en una alternativa, es decir, la idea era mejorar el tipo de contenidos en las aulas (entrevista propia a Roger Domínguez, 6 de julio de 2021). Hoy en día la investigación educativa sobre la enseñanza de la historia ha señalado que enfocarse en los contenidos no es suficiente para el proceso de enseñanza-aprendizaje y es necesario abordar el nivel cognitivo y didáctico (Pagès y Plá, 2014) para incidir en la formación de la consciencia y el pensamiento histórico. En los últimos años se ha mostrado el agotamiento de los modelos tradicionales de la enseñanza de la historia (Estepa Giménez, 2017). Las nuevas propuestas parten de la reflexión en torno a las grandes transformaciones que han experimentado los Estados-Nacionales, en el marco de los procesos de globalización, que cuestionan a la historia nacional, tanto en su papel de cohesionadora social, como en los mecanismos que empleó esta vertiente de la historia para enraizar entre los ciudadanos el sentido de unidad y forjar una identidad nacional (Carretero, 2007; Carretero y Kriger, 2012). La Historia nacional siempre privilegió la versión de la cultura dominante y dejó sin voz a los "otros", a la "Gente sin Historia" (Wolf, 1994). Paradójicamente, su programa homogeneizador, excluyó de la historia a aquellos que conformaban el cuerpo de la nación.

Pero este hecho no es aislado, sino que va de la mano con las transformaciones del oficio del historiador. Desde la década de los setenta la renovación historiográfica que asistió a la Escuela Francesa de los Annales y la Historia Social Inglesa permitió el cuestionamiento de las grandes narraciones sobre las que se construyeron las naciones (Dosse, 2006). Así, obras como la de Nataly Zemon Davis (2013), El regreso de Martín Guerre o El queso y los gusanos de Carlos Ginzburg (1999) son textos fundacionales que llamaron la atención sobre la necesidad de mirar las otras historias que estaban relegadas u opacadas por las grandes narraciones. En ese sentido podemos ver que convergen en un mismo 
momento el cuestionamiento tanto de la Historia "oficial" y su utilidad para la construcción de la nación, como el sesgo de la historia académica de privilegiar los grandes hechos o hechos significativos, como se le llamaban en su momento, una coincidencia sobre la que valdría la pena reflexionar en otro momento.

Por otra parte, como es bien sabido, esa historia oficial privilegió el uso de fuentes oficiales, y no solo por su origen de producción, sino por el mismo depósito, los archivos nacionales, pensados para el resguardo de la memoria nacional (Mendo Carmona, 1995), o como esos Lugares de Memoria (Nora, 2008) a donde se recurre para revitalizar el sentido de pertenencia, en este caso, en donde se acude a expurgar la historia.

Regresemos a la renovación de la Historia para vincularla a nuestro tema de interés. Estas transformaciones que asistieron a la historiografía en la década de los setenta y en la que convergen diversos factores que permitieron mirar a la Gente sin Historia, tuvo que enfrentar un problema importante: las fuentes. La diversificación de temas de estudio también repercutió en la diversidad de fuentes y obligó a los historiadores a acercarse a otras disciplinas y otras disciplinas se acercaron a la historia, lo que comenzó a permitir la inter y la multidisciplina. Los préstamos teóricos y metodológicos a la antropología, sociología, geografía, arqueología, psicología, y muchas otras ciencias sociales, enriquecieron el quehacer de la historia, las fuentes se diversificaron y se observaron desde diferentes lentes y escalas, dando como resultado nuevos discursos históricos, nuevos resultados, reflexiones novedosas y voz para los agentes que antes estaban silenciados. Desde aquel momento, cualquier objeto que fuera indicio de la actividad humana se transformó en una huella para reconstruir la historia (Burke, 1996).

Por otra parte, frente a la idea de que la globalización terminaría por homogenizar los patrones culturales, las comunidades (lo local) se convirtieron en un espacio para la defensa de la identidad. Ante el vaticinio de la muerte del Estado-Nación, vemos hoy día emerger llamados de los líderes mundiales en defensa de los intereses nacionales; pero a diferencia de la época dorada del nacionalismo, la homogeneidad ya no es un objetivo, sino el reconocimiento de la diversidad, la pluralidad como un valor para la convivencia social. En este contexto, las preguntas obligadas son: ¿qué papel juega la historia local en el marco de la historia nacional? ¿Cómo vincular la historia de la localidad a las grandes narraciones? ¿Cuáles son las estrategias didácticas que pueden favores la enseñanza de la historia partiendo de la historia local? En este contexto, nuestro objetivo es describir una experiencia de enseñanza de la historia basada en el objeto doméstico como una estrategia para la enseñanza de la historia que permite potenciar en pensamiento y consciencia histórica como una alternativa a la crisis de la historia de la enseñanza de la historia de corte nacionalista.

La hipótesis que guía este estudio propone que, en el contexto actual, la enseñanza de la historia en las aulas debe considerar a la historia local como relato fundamental para la formación, consolidación y arraigo de las identidades. En tal caso, el propósito vertebral de la enseñanza de la historia es encontrar, en el medio que rodea a los estudiantes, aquellas huellas, improntas o indicios significativos de la actividad pasada que permita asociar su historia con los relatos nacionales. Convertir a los objetos que rodean a los individuos en objetos didácticos (Llonch y Molina, 2012). El trabajo del historiador, junto con el docente de historia, 
será construir y reconstruir los discursos de cada indicio hallado, dando voz a los papeles, objetos, imágenes, edificios y cualquier elemento pretérito que nos ayude a enseñar, a materializar el ayer para que sea tangible, perceptible a los sentidos y, por lo tanto, un medio por donde los alumnos y la personas en general conozcan, comprendan y reflexionen sobre su pasado.

Como hemos indicado, este documento tiene como objetivo exponer una experiencia didáctica para mostrar una propuesta de innovación educativa que parte de la historia local y regional, por lo que centran en exponer una metodología aplicada para contribuir a diseñar nuevas formas de didáctica de la historia que contribuyan a mirar desde otra perspectiva el potencial que tiene la enseñanza de la historia basada en el objeto. De acuerdo con (Pagès y Plá, 2014: 24-25) el fin de esta metodología es "tratar de resolver problemas cuyas respuestas pueden ser generalizables, a fin de establecer principios de enseñanza, modelos didácticos". Así empleando esta metodología pretendemos mostrar la importancia que tienen los objetos domésticos en la enseñanza de la historia; como hemos señalado líneas arriba, desde la perspectiva de la historiografía como disciplina que reconstruye el pasado estos objetos han cobrado un lugar importante, ahora la propuesta es mirar estos objetos como objetos didácticos para la enseñanza de la historia (Llonch y Molina, 2012). A través de esta estrategia didáctica y su práctica, pretendemos mostrar un modelo para enseñar a pensar históricamente, al mismo tiempo que demuestra que la interacción con los objetos o huellas del pasado son clave en la enseñanza de la historia para los procesos de enseñanza aprendizaje en una etapa en la que la historia nacional se ha erosionado. Se ha demostrado que la interacción "con objetos, restos materiales y artefactos producidos por las sociedades" favorecen un aprendizaje dinámico, activo y participativo (Gómez Carrasco y Prieto Prieto, 2016:8); y el Museo Móvil plantea ser un espacio dinámico, activo y participativo.

\section{El patrimonio cultural, los objetos del pasado y el pensamiento histórico}

Los objetos que se presentan en El Museo Móvil tienen un origen doméstico. La casa es el espacio en donde todos los seres humanos adquirimos nuestras primeras y más sólidas identidades, es el lugar primario de sociabilidad de la educación llamada informal, pero en realidad, es donde se construyen los primeros y muy perdurables utillajes mentales (García Cárcel, 1990:180), ${ }^{1}$ se personalizan los sentidos, el entendimiento de lo diario, la cosmovisión. De acuerdo con Reyna Sánchez Estévez "se entiende por casa ese lugar que el sujeto ocupa en el mundo, en el que se sitúa, que lo hace aparecer frente a sí mismo y frente a los otros, es decir, que le proporciona una ubicación espacio-temporal, una pertenencia y, por ende, una identidad" (Sánchez Estevez, 2012:111). Nosotros agregaríamos que esa identidad está fincada en una cultura, en ese entretejido simbólico en el que interactúa la persona y que se materializa en formas simbólicas que pueden ser artefactos, vestidos, prácticas, concepciones, etc. (Giménez Montiel, 2005) Todo puede ser cultura y, como tal, parte fundamental de la identidad de una familia, un grupo, una comunidad.

Con lo antes dicho, la casa es un espacio de acumulación de objetos, en donde la gran mayoría son consumibles y perecederos y por lo tanto con mayor 
tendencia a ser desechables cuando concluye su vida útil; pero otros tienen una carga simbólica profunda creada y acrecentada con el tiempo. Así, el viejo radio que perteneció al abuelo ya difunto adquiere un valor simbólico que hace que se mantenga por mucho tiempo en su mismo sitio -incluso descompuestotransformándose en un Lugar de Memoria (Nora, 2008) en donde se revitaliza la identidad familiar. Tíos, hermanos, hijos, nietos, biznietos y otros familiares miran el antiguo aparato, pasan junto a él, reflexionan sobre él, platican sobre su historia, la transmiten a las nuevas generaciones, e incluso se acercan ex profeso para recordar al abuelo y con toda esta mística reafirman sus raíces familiares. Lo mismo pasa con retratos, relojes, vajillas, fotografías, documentos, imágenes religiosas, muebles de todo tipo y muchos objetos más que se resguardan en el ambiente cotidiano como reliquias del pasado familiar que exaltan los sentimientos identitarios y de pertenencia. Dichos objetos son, en primera instancia, referentes de la familia poseedora para quien son representaciones de su historia y de sus ascendientes.

Sin embargo, estos objetos, reconocidos como Lugares de la Memoria, poseen características simbólicas que pueden ser compartidas por una generación, una comunidad local, una región o una nación, es decir, los objetos antiguos que se resguardan en las casas son formas simbólicas o depósitos de cultura de un pueblo, por lo que también son un referente relevante para las identidades colectivas, pues si bien existen ahora en manos de una familia, a veces como pieza única, en su momento fueron objetos comunes en muchos hogares, que perduran en la memoria de muchas personas. Ahora bien, ¿son estos objetos parte del Patrimonio Cultural? De acuerdo con la definición de Bonfil Batalla:

\footnotetext{
El Patrimonio Cultural es un acervo de elementos culturales -tangibles unos, intangibles los otros- que una determinada sociedad considera suyos y de los que echa mano para enfrentar sus problemas; para formular e intentar realizar sus aspiraciones y sus proyectos; para imaginar, gozar y expresarse, que no solo se limita a objetos del pasado, sino también a las costumbres, conocimientos, sistemas de significados, habilidades y formas de expresión simbólica. (Bonfil Batalla, 1993:21)
}

No obstante, de acuerdo con la normatividad mexicana vigente, los objetos simbólicos domésticos no se circunscriben en esta esfera, salvo excepciones de objetos artísticos de reconocido valor. Los objetos cotidianos antiguos, vulgarmente llamados "antigüedades" no suelen valorarse y se venden por todos lados sin ninguna regulación. De hecho, en el caso mexicano, la ley federal sobre monumentos y zonas arqueológicas, artísticos e históricos reconoce tres tipos de bienes sujetos a protegerse: los arqueológicos (vestigios naturales prehistóricos y de culturas previas a la conquista), los monumentos artísticos (bienes muebles e inmuebles que revistan valor estético relevante) y los monumentos históricos a los que se reconoce como: los bienes vinculados con la historia de la nación, a partir del establecimiento de la cultura hispánica en el país, en los términos de la declaratoria respectiva o por determinación de la Ley (artículo 35). Esta ley reconoce como monumentos históricos:

1. Los inmuebles construidos en los siglos XVI al XIX, destinados a templos y sus anexos; arzobispados, obispados y casas curales; seminarios, conventos o cualesquiera otros dedicados a la administración, divulgación, enseñanza o práctica de un culto 
religioso; así como a la educación y a la enseñanza, a fines asistenciales o benéficos; al servicio y ornato públicos y al uso de las autoridades civiles y militares. Los muebles que se encuentren o se hayan encontrado en dichos inmuebles y las obras civiles relevantes de carácter privado realizadas de los siglos XVI al XIX inclusive.

2. Los documentos y expedientes que pertenezcan o hayan pertenecido a las oficinas y archivos de la Federación, de los Estados o de los Municipios y de las casas curiales.

3. Los documentos originales manuscritos relacionados con la historia de México y los libros, folletos y otros impresos en México o en el extranjero, durante los siglos XVI al XIX que, por su rareza e importancia para la historia mexicana, merezcan ser conservados en el país.

4. Las colecciones científicas y técnicas podrán elevarse a esta categoría, mediante la declaratoria correspondiente.

Como podemos ver, en las leyes que protegen el patrimonio resalta una gran ambigüedad en cuanto a la valoración de los objetos para ser reconocidos, valorados y recuperados. Existen piezas muy antiguas, incluso coloniales, que se venden en el comercio, muy en particular las imágenes religiosas; pero también otros bienes como relojes, muebles, libros, artefactos musicales, monedas, y muchos otros. Así se pierden invaluables piezas que salen muchas veces del país, que como ya se ha dicho, refieren a la identidad yucateca (en este caso), familiar y colectiva. Objetos que son huellas del pasado y fundamentales para una estrategia didáctica de la historia con origen en lo local.

A diferencia de las propuestas que definen el patrimonio en términos de utilidad para la formación de una identidad nacional, nosotros preferimos partir de las ideas de Bonfil Batalla cuando menciona y critica que el Patrimonio Cultural no es otra cosa que "una selección de ciertos bienes de diversas culturas en función de criterios esencialmente occidentales", a lo que también podemos añadir intereses económicos, políticos, religiosos, de las élites, de los magnates del turismo, por mencionar algunos. Por lo mismo, Bonfil Batalla (1993:19) se pregunta: "¿en qué consiste el patrimonio cultural de un pueblo [comunidad local], es decir, cuáles bienes tangibles o intangibles constituyen ese patrimonio?” Las respuestas a esta pregunta son muchas: cada pueblo, comunidad o localidad deposita y expresa sus identidades asociadas a lo tangible o intangible y podríamos llevarnos muchas sorpresas, pues las comunidades pueden construir sus lugares de memoria paralelos a las instituciones oficiales (gobierno, Iglesia, Escuela, etc). Veamos un caso.

En nuestro medio local existen múltiples ejemplos de comunidades que construyen su identidad desde el ámbito local. Uno de ellos es el caso de la comunidad de Tahdziú, al sur del Estado de Yucatán, México, cuya identidad religiosa no se encuentra en el edificio de la parroquia principal, del centro de la comunidad, que data de la época colonial, sino en una sencilla capilla de láminas construida en un barrio del pueblo. Aunque en condiciones precarias, el valor simbólico de este templo es superior al "institucional". En esa capilla se realizan devociones sincréticas de gran relevancia, donde se plasma la historia; pero al cual la historia "oficial" no le presta atención, aunque ahí está depositada parte importante de la historia de la comunidad. 
Misma situación hallamos en muchos objetos de las casas, que como hemos dicho, si bien en primera instancia responden a una identidad familiar, de igual manera son objetos de representación colectiva. Pensemos por ejemplo en una sala yucateca o maya ${ }^{2}$ de los años treinta del siglo XX, típica y común, que en su momento fue de poco valor, por lo que una masa de población pudo tener acceso a ellas. Un simple conjunto de muebles, pero en la identidad familiar responden a una historia particular de mucho sentimiento para los propietarios, mientras que, en lo colectivo, se asocian a una historia de la producción de la madera de cedro en Yucatán que trajo un corto auge a la región oriente de la península (Cortés Campos, 2013), historia que no vamos a explicar aquí, pero que se refleja en un mueble, que, en tal caso, se convierte en una huella del pasado y con la cual podemos enseñar historia en el aula (historia social, historia económica, historia de la vida cotidiana); un objeto con el que interactúan diariamente los estudiantes. En la producción de esos muebles intervinieron muchas personas de la comunidad: carpinteros, aserraderos, comerciantes, quizá un círculo cercano a nuestros estudiantes por sus ascendentes. De hecho, es muy posible que los estudiantes puedan realizar ejercicios de historia oral, dentro de su propia familia, a partir de un objeto, como el caso de los muebles de cedro, y como este ejemplo muchos otros que potencializan la reflexión histórica y de identidad entre nuestros alumnos desde el ámbito local. Una reflexión en torno a la emergencia de esos oficios y su desaparición a lo largo del tiempo (pensemos en los herreros que hoy en día están desapareciendo), nos ayudarían a reflexionar los cambios que experimentan las comunidades en el contexto de la globalización y la mercantilización. Antes las comunidades generaban sus bienes y servicios, hoy las adquieren todo del mercado, presente y pasado están en estos objetos.

Lo mismo podemos decir de una imagen religiosa, identidad de una familia, pero que refleja los intereses de los grupos religiosos (clero secular o regular) que la difundieron, y más aún, la imagen nos remite a los imaginarios particulares y de las colectividades. Una imagen que, a pesar de ser parte del mundo simbólico, la práctica las pudo convertir en un lugar de memoria para una comunidad: pensemos (por ejemplo) en los patronos familiares y sus festejos en las que participa la comunidad, rosarios en el barrio, novenas, promesas convertidas en festejo y jolgorio popular, y mucho más. Podemos reflexionar en los cambios y continuidades que guardan muchas de estas prácticas, así poder mostrar que la historia está hecha no solo de cambios, sino también de continuidades.

La idea de tomar estos objetos, revalorarlos, estudiarlos como documentos legibles, conservarlos y utilizarlos para la enseñanza de la historia y el reconocimiento y difusión de las identidades, va muy acorde a la propuesta de Orhan Pamuk (2012:56) quien es su obra The innocence of objects. The Museum of innocence, Estambul, reflexiona en torno a dos tipos de museos: los grandes museos nacionales y los pequeños que suelen ser particulares y repletos de historias locales, fabulosas y noveladas. Para Pamuk, los primeros retratan grandes historias de tendencia nacional o regional, mientras que los museos pequeños se convierten en proyectos muy cercanos con las comunidades, en donde se expresan las historias que identifican a la comunidad, se resguardan objetos de poco valor artístico y económico, pero de gran significado para la gente cercana. A través de estos museos la gente expresa sus orgullos personales y comunes y las piezas 
llegan a valorarse de forma muy profunda, son los tesoros de la comunidad con significados particulares.

En la renovación que asiste a la enseñanza de la historia sus objetivos se modifican al cuestionar su papel de simple creadora de la identidad nacional "adoctrinante" y plantear el objetivo de moldear para pensar históricamente, para desarrollar en ellos un pensamiento crítico que les permita reflexionar sobre su devenir, sobre la continuidad de los problemas sociales locales y nacionales, sobre la agencia política, sobre los principios y valores que pueden hacer de un individuo un agente de cambio en asociación con otros; pero, sobre todo, para fortalecer el sentimiento de identidad, de comunidad, de arraigo, que les permita actuar como ciudadanos críticos y reflexivos.

De acuerdo con Santisteban Fernández (2010), en la actualidad se debe abandonar la enseñanza de la historia basada en la memorización de fechas, personajes, cuestionarios de respuesta dada. Hoy en día se debe privilegiar la enseñanza que conduzca a los estudiantes a pensar históricamente, lo que supone cuatro dimensiones: temporalidad, las formas de representación de la historia, la imaginación/creatividad y la interpretación histórica. Desde la década de los sesenta se han impulsado diversas experiencias que han consolidado la enseñanza de la historia desde diversas tradiciones, cada una de ellas ha puesto su acento en un aspecto que ha considerado clave para su realidad. Así, la tradición británica apostó por cuestiones como la posibilidad generar en los estudiantes, con el aprendizaje de la historia, habilidades para comprender relaciones causaefecto, cambios y continuidades, las características de la explicación histórica y la noción de empatía histórica. Por su parte, la tradición alemana trabajó en torno a la idea de conciencia histórica que permitiría atar el pasado, presente y futuro. La tradición canadiense se preocupó por cuestiones como la intersubjetividad en la construcción del pasado, el problema de la evidencia histórica, el cambio y la continuidad, la relación causa-efecto, la posibilidad de recrear el pasado desde sus actores y la dimensión ética en el trabajo histórico (Seixas y Peck, 2004, Seixas, 2017). Podemos sinterizar estas iniciativas para renovar la enseñanza de la historia en el paradigma del pensamiento histórico en el siguiente conjunto de conceptos de segundo orden o metodológicos: fuenteprueba, causas-consecuencia, empatía histórica, cambios y continuidad, relato e interpretación, relevancia histórica, dimensión ética, conciencia histórica, entre otros (Domínguez et al, 2017).

Una de las dimensiones que nos gustaría destacar es la relacionada con el tiempo y la conciencia histórica, por su importancia para una didáctica del objeto. De acuerdo con la tradición alemana, la enseñanza de la historia (como conciencia histórica) supone un aprendizaje de la disciplina para la vida diaria, así el objetivo es el conocimiento del pasado como medio para comprender los problemas del presente; en ese sentido, la consciencia histórica proporciona una brújula temporal para situarse en el mundo, porque es su pasado, su presente y sus rutas al futuro; en este contexto la conciencia histórica se convierte en una valiosa herramienta para enfrentar el futuro (Seixas, 2017). Pagès Blanch y Santisteban Fernández (2010) proponen construir un proceso de enseñanza aprendizaje del tiempo histórico en la que el estudiante logré establecer la relación entre pasado, presente y futuro. Una idea de temporalidad que contribuya a que los estudiantes puedan encontrar en el pasado una explicación del presente. Aunque 
consideramos que no es posible proyectar un futuro, podemos reflexionar sobre escenarios de posibilidad con base en el pasado y presente. Desde nuestra perspectiva una estrategia didáctica para conectar el presente, el pasado y futuro y trabajar la consciencia histórica en aula debe ser a través de una historia significativa (Seixas y Peck, 2004) fincada en el patrimonio doméstico y en el uso de objetos como estrategia didáctica.

Los planteamientos para una enseñanza de la historia basada en los objetos (didáctica del objeto) tienen una larga tradición en las ciencias sociales y las humanidades. Desde la arqueología los trabajos de Henderson y Levstik (2016) en el ámbito angloamericano han demostrado su utilidad para pensar sobre las sociedades del pasado; en el caso español se ha revelado su potencial para la educación primaria y el desarrollo del pensamiento histórico (Arias et al, 2016). O experiencias didácticas que muestran su pertinencia para la formación de profesionales con herramientas innovadoras para la enseñanza de la historia (Llonch-Molina y Parisi-Moreno, 2018). Joan Santacana I Mestre y Nayra Llonch Molina (2012) han destacado las virtudes de una didáctica basada en los objetos; así una estrategia didáctica basada en el objeto permite relacionar objeto con concepto, por lo que el objeto se transforma en un elemento referencial del concepto. Por otra parte, el objeto capta la atención funcionando como un imán; además permite dinamizar estrategias didácticas basadas en los métodos hipotético-deductivo e inductivo; también posibilita estimular la imaginación. Al mismo tiempo, pueden fungir como inclusores para incorporar nuevos conocimientos y, sobre todo, son soportes de la memoria.

Estos atributos de la didáctica del objeto los consideramos relevantes en la presente propuesta de innovación educativa porque El Museo Móvil es espacio caracterizado por resguardar objetos del pasado que remiten a una historia local. Sus objetos son huellas de una historia compartida por lo que son un soporte de la memoria local capaces de despertar la imaginación histórica vinculada al propio estudiante, por lo que pueden fungir como ese inclusor capaz de tender el puente entre el pasado-presente-futuro articulado a un espacio y a una sociedad, en otras palabras, el Museo Móvil como depósito del patrimonio doméstico local es una estrategia didáctica para formar la conciencia histórica.

\section{El Museo Móvil: la historia local y regional}

Pensando en fomentar este tipo de museos que resguarden la memoria regional, nació la idea de El Museo Móvil que en realidad es un proyecto que tiene como objetivo llevar a las escuelas secundarias y preparatorias de Yucatán (sin omitir otras posibilidades) una colección de objetos con una carga simbólica, identitaria e histórica regional, con el objeto de generar conciencia del valor patrimonial de estas piezas, y motivar a la estimación de la materialidad y la recuperación de sus discursos para la enseñanza de la historia y la continuidad de las identidades. Se trata de piezas seleccionadas por su significado para la sociedad yucateca a las cuales se les ha construido un discurso que pretende enseñar valores cívicos, amor a nuestra tierra, sensibilidad a los problemas sociales, las reivindicaciones de las luchas históricas revolucionarias, la lucha de las mujeres, el compromiso social de todos, el deber para con la patria, las libertades y los derechos de todos, entre otros 
temas de gran relevancia, y todos vinculados con la historia nuestra, sin perder la perspectiva nacional e internacional.

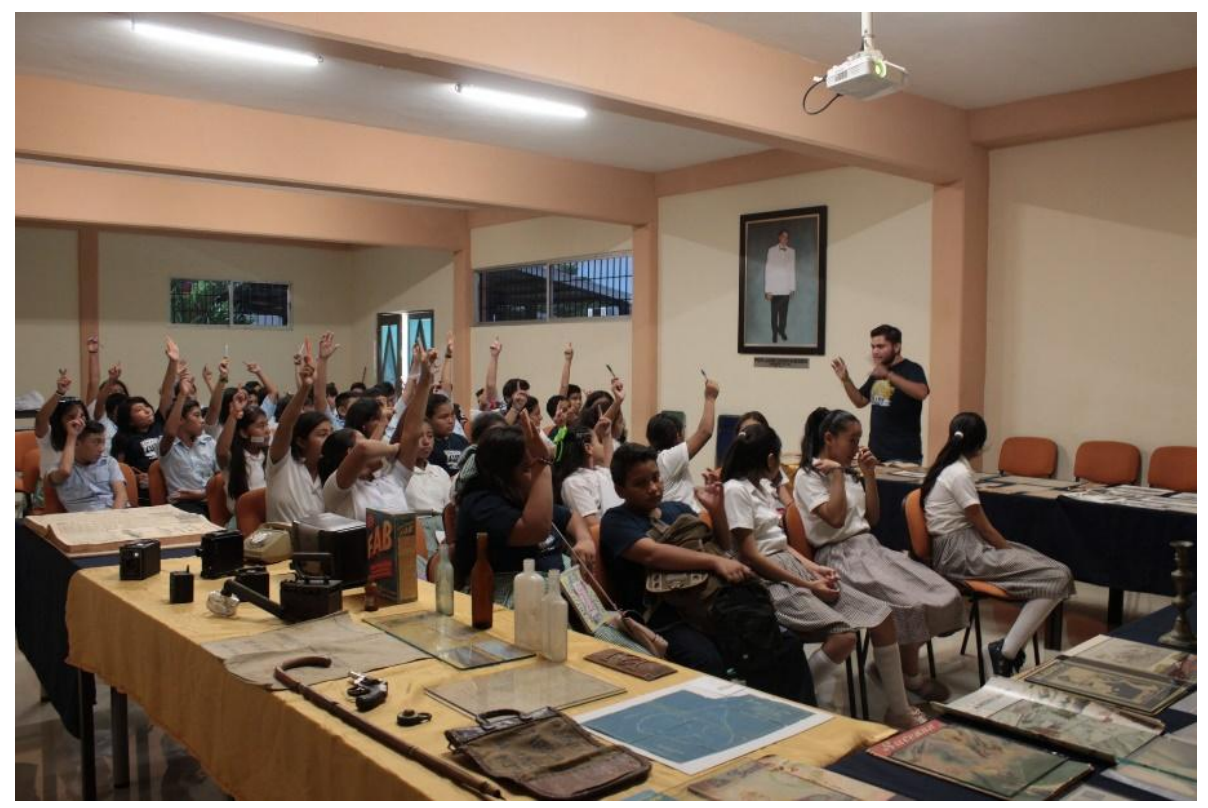

Figura 1.

Presentación de El Museo Móvil en la escuela secundaria Eduardo Urzaiz Rodríguez, Mérida, Yucatán, 2019.

Fotografía de Gabriela Escamilla Jiménez.

Al mismo tiempo, el Museo permite que los estudiantes establezcan un vínculo con el pasado y el presente. Así, las formas simbólicas remiten a su pasado para reconocer las prácticas de su presente. De igual manera y no de menor importancia, El Museo Móvil es un escenario real de aprendizaje para nuestros alumnos de la licenciatura en historia de la UADY, pues en él desarrollan herramientas como la oratoria, la didáctica, el enfrentarse a un grupo real, la relevancia de la difusión, el deber del historiador para generar crítica social y ciudadanía, el aterrizaje de la abstracción teoría, entre otras importantes resultados. 


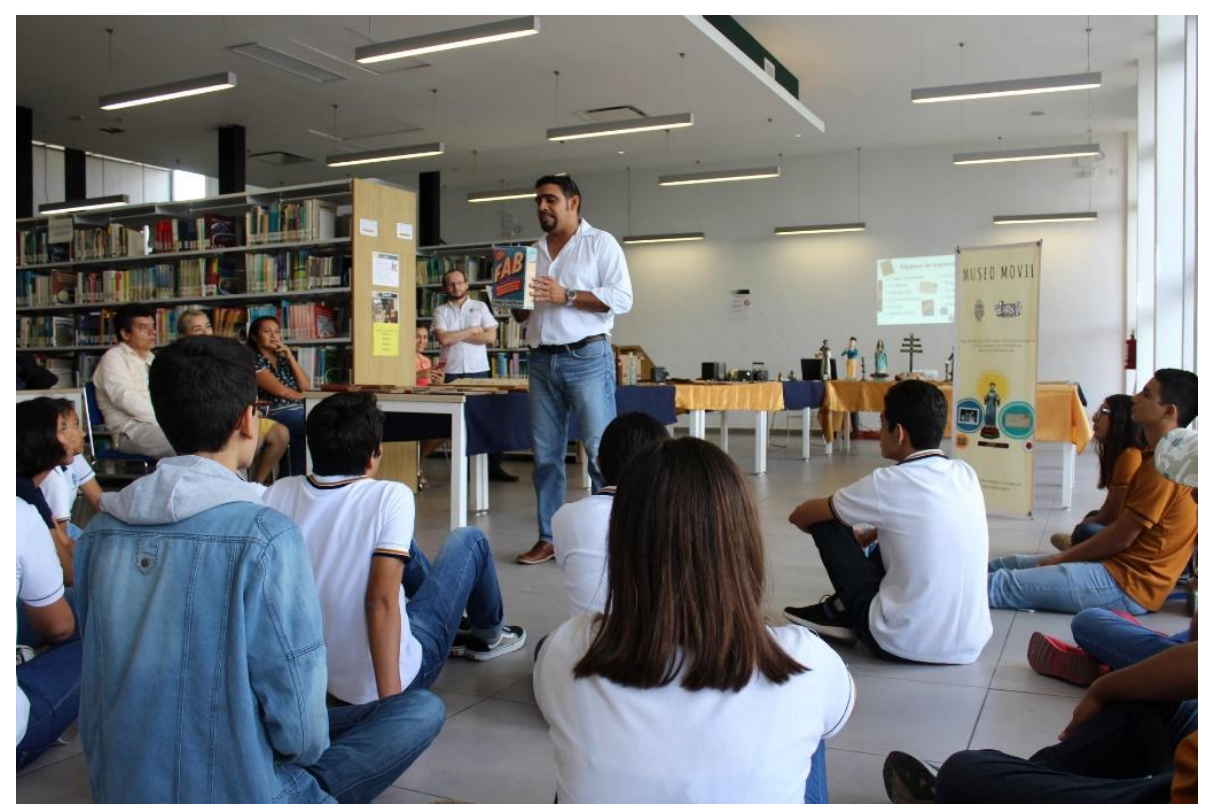

Figura 2.

Presentación de El Museo Móvil en la Escuela Preparatoria

$\mathrm{N}^{\circ} 2$ de la Universidad Autónoma de Yucatán. 2019.

Fotografía de Ramón Soberanis Pech.

El Museo Móvil se ha organizado en las siguientes temáticas:

- Objetos de origen porfiriano: se trata de piezas que se utilizaron en el tiempo del régimen de Porfirio Díaz, que coincide en Yucatán con el tiempo del auge henequenero. El conjunto se compone de documentos originales de haciendas henequeneras tales como cuadernos de cuentas con las listas de los trabajadores, planos de haciendas, propaganda de la época para refaccionar la maquinaria, cartas personales de hacendados, fotografías, entre otros documentos de tipo familiar. También se incluyen fichas de haciendas originales, un revolver en desuso fechado en 1880, relojes, numismática, entre otras piezas. Objetos de origen porfiriano: se trata de piezas que se utilizaron en el tiempo del régimen de Porfirio Díaz, que coincide en Yucatán con el tiempo del auge henequenero. El conjunto se compone de documentos originales de haciendas henequeneras tales como cuadernos de cuentas con las listas de los trabajadores, planos de haciendas, propaganda de la época para refaccionar la maquinaria, cartas personales de hacendados, fotografías, entre otros documentos de tipo familiar. También se incluyen fichas de haciendas originales, un revolver en desuso fechado en 1880, relojes, numismática, entre otras piezas.

- Tecnología del pasado: este rubro incluye radios antiguos, cámaras fotográficas de principios del siglo XX, planchas de metal, máquinas de escribir, quinqués, viejos ventiladores de escritorio y teléfonos antiguos.

- Hemerografía: consiste en una colección de periódicos del siglo XX, de Campeche y Yucatán. Se incluyen también algunas muestras aisladas de finales del siglo XIX. 
- Libros antiguos: conservamos una colección de libros antiguos, sobre todo del siglo XX. Resalta un conjunto de libros de texto del tiempo del Porfiriato y algunos ejemplares del siglo XVIII y XIX de diversos temas.

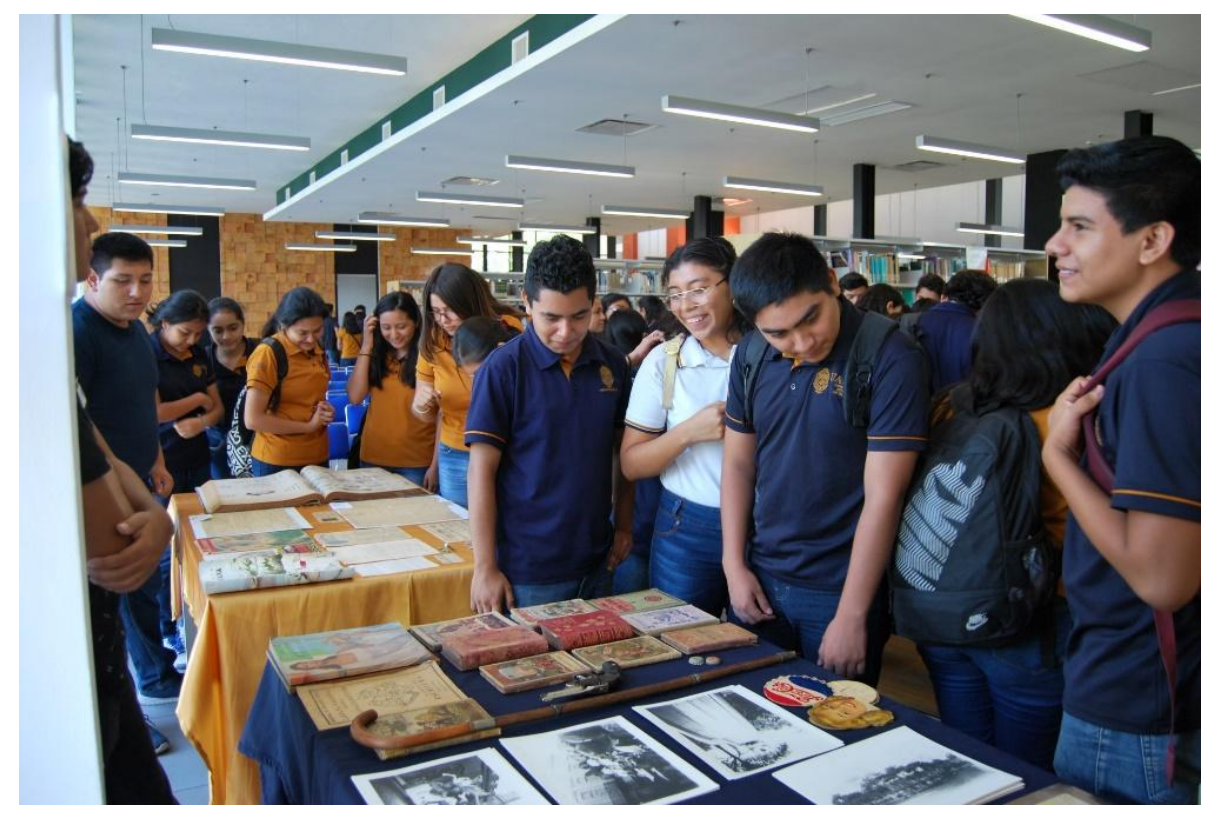

Figura 3.

Presentación de El Museo Móvil en la Escuela Preparatoria

$\mathrm{N}^{\circ} 2$ de la Universidad Autónoma de Yucatán. 2019.

Fotografía de Ramón Soberanis Pech.

- Cartas personales: se trata de una colección de un centenar de cartas personales de diferentes temas: comerciales, familiares, amistosas y amorosas.

- Numismática: nuestra colección de monedas y billetes, aunque pequeña, contiene piezas relevantes como bilimbiques carrancistas, fichas de haciendas, monedas de plata del tiempo porfiriano, billetes de la primera mitad del siglo XX, y muchos otros de tiempos contemporáneos.

- Folletería: este rubro consiste en una amplia colección de propaganda comercial y religiosa del siglo $\mathrm{XX}$, volantes que promueven productos locales, nacionales e internacionales, carteles de cine, teatro, festejos populares, inauguraciones, ordenes de bailes públicos, entre otros muy variados que nos retratan a la sociedad que nos antecede. 


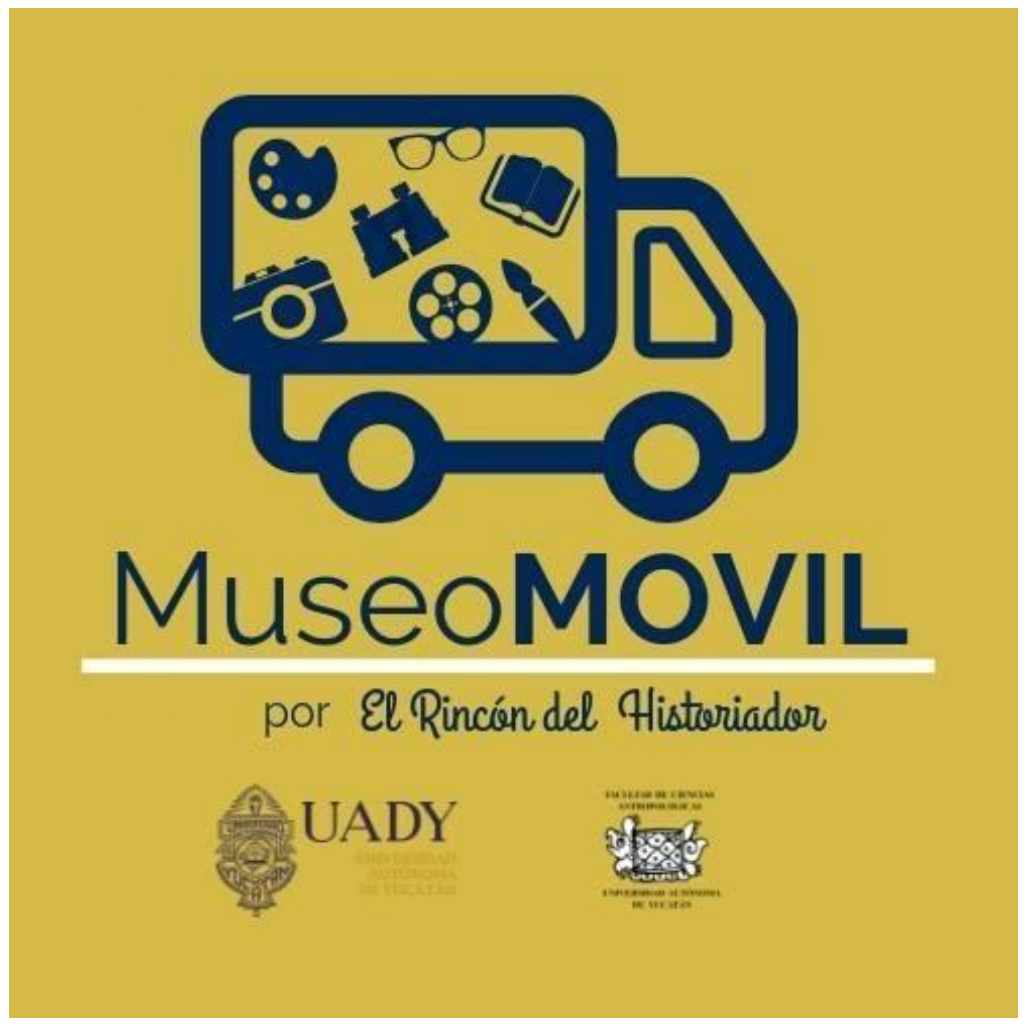

Figura 4.

Propaganda de El Museo Móvil. Diseñó Juan Pablo Passarelli Serrano.

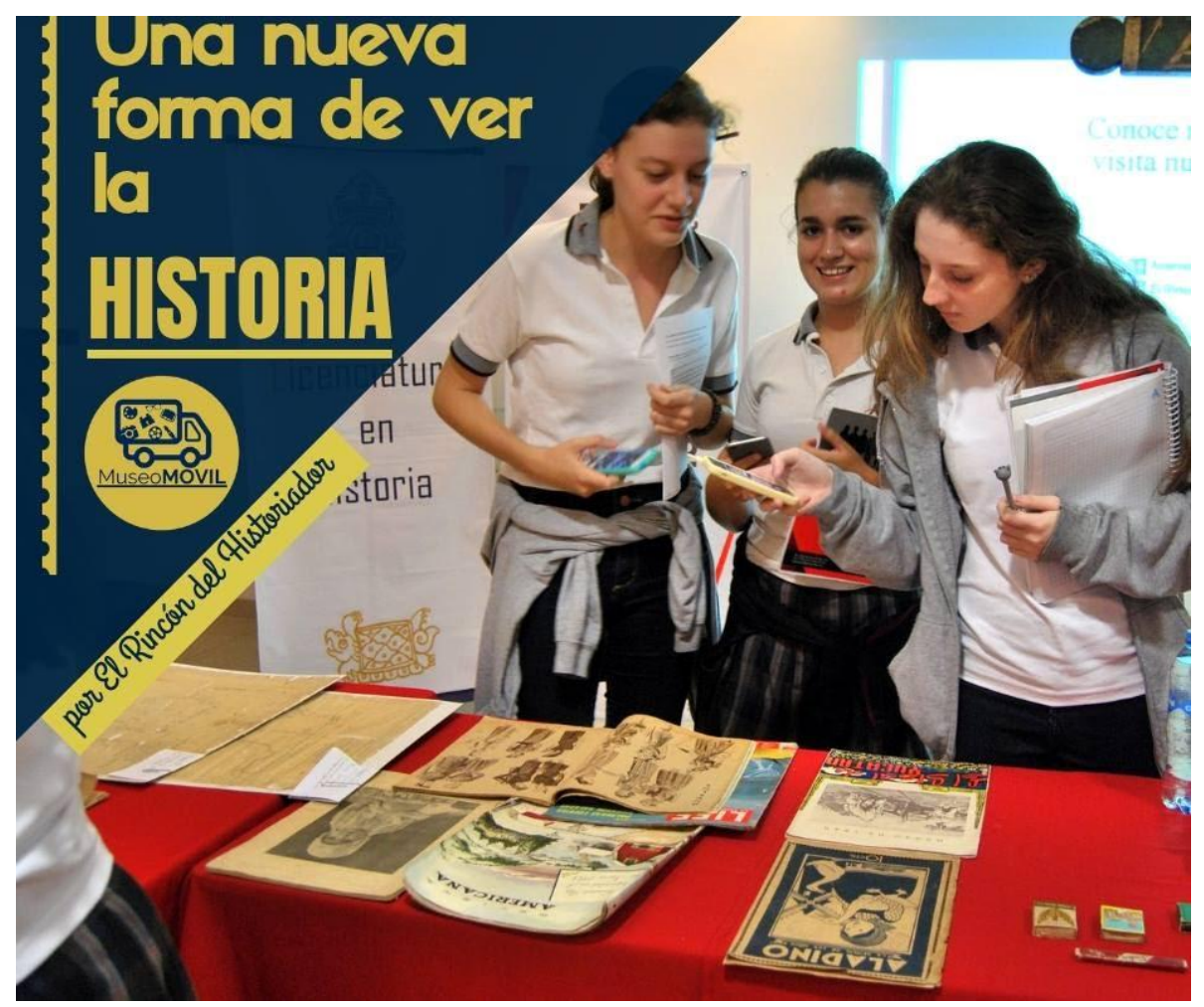

Figura 5.

Propaganda de El Museo Móvil.

Diseñó Juan Pablo Passarelli Serrano. 
- Fotografías antiguas: se conserva una colección de más de 300 fotografías de origen familiar, pero que nos muestran escenas de la ciudad de Mérida, del puerto de Progreso, de las ruinas mayas y de muchos otros temas de la vida cotidiana, sobre todo en Yucatán.

- Imágenes religiosas: se trata de un conjunto de imágenes, tanto de bulto como litografías y posters, de diferentes épocas. Contamos con piezas fechadas para el siglo XVIII y otras para el XX. Con ellas abordamos temas como el arte sacro y sus problemas de protección, las prácticas religiosas locales, la iconografía y el control social religioso.

- Industria yucateca y foránea: en este apartado presentamos un conjunto de objetos que representan a la producción industrial local extinta: botellas antiguas de la Pino y el Soldado de Chocolate, algunas con líquido original. También exhibimos una colección de botellas de la cervecería yucateca de mediados del siglo XX. Contamos con una muestra de la producción de cerillos yucatecos, hoy inexistentes. Otros productos de arraigo local, aunque importados son la Pepsi, Emulsión de Scott, insecticida Flit, detergente Fab, medicamentos antiguos y muchos otros.

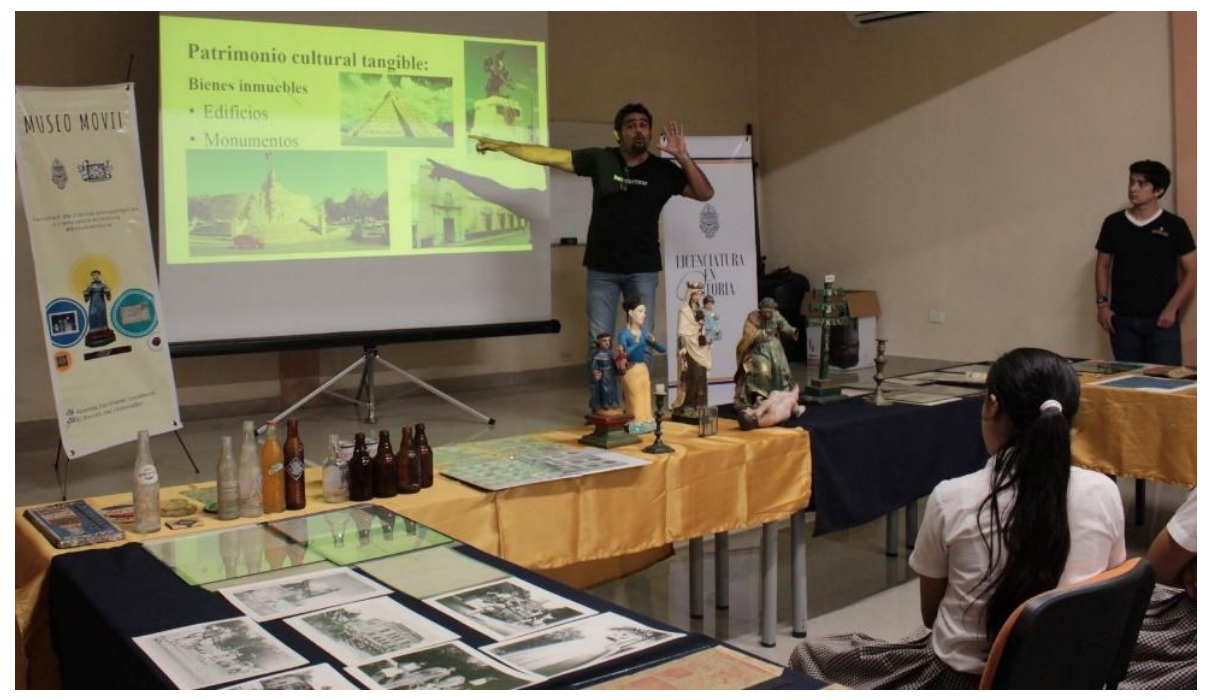

Figura 6.

Presentación de El Museo Móvil en la escuela secundaria

Eduardo Urzaiz Rodríguez, Mérida, Yucatán, 2019.

Fotografía de Gabriela Escamilla Jiménez.

Ahora bien, la presentación de estas piezas tiene una sencilla pero efectiva metodología que consiste en una exposición física y discursiva en cuatro momentos. El primero es una reflexión sobre el valor patrimonial de los objetos, su origen doméstico, su valor histórico como pieza y como documento, su significado para las familias y la falta de aprecio por desconocimiento. El segundo momento plantea el proceso de recuperación, conservación y difusión que se está ejecutando a través de El Museo Móvil. El tercer momento aborda la narración de la historia de algunos de los objetos, la reflexión que brinda a la identidad, a la crítica social, al deber, al patriotismo, al género o a cualquier tema social que ayude en la formación de los participantes. Un cuarto momento es la concientización de la relevancia de este proyecto y la solicitud de apoyo para difundirlo en las redes 
sociales y entre sus familiares, cerrando con esto la exposición que dura una hora quince minutos aproximadamente.

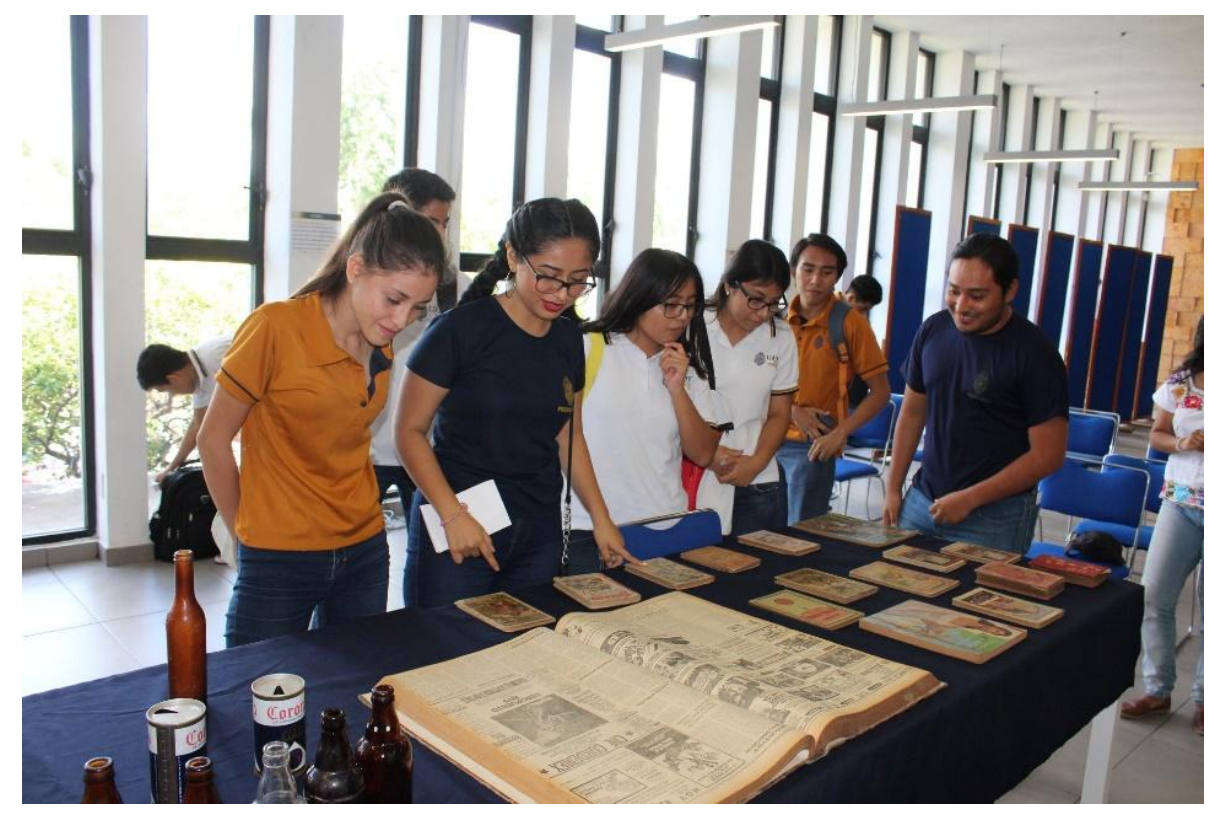

Figura 7.

Presentación de El Museo Móvil en la Escuela Preparatoria

Nº 2 de la Universidad Autónoma de Yucatán. 2019

Fotografía de Ramón Soberanis Pech.

Como ejemplo del discurso que se le da a un objeto del museo tenemos el caso de una caja de detergente $\mathrm{FAB}$ de los años cincuenta, que por casualidad se conservó en el fondo de un viejo armario. Esta pieza, que en otro momento sería basura, se convierte en un excelente material para discutir y comprender el fenómeno lingüístico yucateco vigente que nomina a cualquier detergente como FAB, por ser aquella marca la primera que llegó a la península y que transformó las prácticas de higiene, lavado y limpieza de ropa, dejando atrás usos que incluso tenían origen prehispánico, como por ejemplo el lavado con ceniza o el famoso "sancochado"[3]. Este objeto puede ser vinculado con un pasado que es compartido, no solo por una familia, sino por una región y el uso del vocablo sigue vigente, así que en este objeto encontramos pasado y presente unidos.

Otro ejemplo lo tenemos en las viejas botellas de la muy conocida Cervecería Yucateca, que nos remiten a una historia económica de gran relevancia para nuestro pueblo, pero también a las antiguas prácticas y creencias en torno a la cerveza como producto alimenticio y de beneficio amplio, como el consumo de la cerveza León Negra, recomendado a las mujeres que acababan de tener un hijo para que produzcan más y mejor leche materna. Estas prácticas y saberes están resguardados en la memoria, sí que vemos de nuevo converger pasado y presente; y es posible reflexionar sobre el destino de esta industria yucateca de la época de la bonanza henequenera en el marco de la globalización, a partir de una vieja botella.

Como estos ejemplos tenemos muchos. Lo relevante es que, para nosotros, los objetos, creaciones del hombre, conllevan un discurso histórico recuperable que suele estar entretejido en los utillajes mentales de los seres humanos y son expresiones de su cultura. Con ellos estudiamos, creamos y enseñamos historia. Recuperamos, conservamos, desciframos y leemos los objetos para las nuevas 
generaciones, los llevamos a un aula que se convierte en un museo, ahí es donde los jóvenes descubren la historia a través de viejos y olvidados artefactos, que solamente han sido resignificados por los historiadores. Pero que al convertirlos en objetos didácticos adquieren otra dimensión.

\section{Reflexiones finales}

En la actualidad, la enseñanza de la historia enfrenta retos que le impone el presente globalizante. La historia necesita hallar nuevos caminos para fortalecer urgentemente las identidades, cultivando la diversidad para generar espacios sanos de convivencia social. En este sentido, la enseñanza de la historia en las aulas se vuelve fundamental, pero también la historia demanda ser inclusiva, y esa inclusión supone también incorporar la historia de las comunidades o las regiones. Los objetos son Lugares de Memoria que todavía conservan "inconscientemente las comunidades", son piezas fundamentales para movilizar estos saberes, el Museo Móvil tiene este firme propósito. Para terminar, tenemos que mencionar que el proyecto de El Museo Móvil ha dejado resultados muy satisfactorios:

a) Se ha convertido en una propuesta popular y muy bien aceptada por las escuelas y por los maestros, tanto de secundaria como de preparatoria

b) Más de un millar de niños y jóvenes han sido receptores de este proyecto y han recuperado y revalorado su patrimonio cultural de origen doméstico, lo que se refleja en las retroalimentaciones que llevamos a cabo como medidor de resultados

c) Por lo mismo, pensamos que hemos logrado incidir en el proceso formativo de muchos niños y jóvenes yucatecos, utilizando objetos con un discurso histórico que se relaciona con múltiples aspectos de su identidad, personal, familiar y colectiva.

d) El Museo Móvil se ha convertido en una herramienta didáctica que practican los alumnos de la licenciatura en historia y es también un escenario real de aprendizaje de mucho valor para nuestros estudiantes en donde practican

e) Consideramos que, con El Museo Móvil, podemos incidir en la conciencia histórica de los jóvenes, sobre todo cuando reconocemos que los objetos son Lugares de Memoria que activan el pasado personal, familiar y comunitario.

En nuestro proyecto, todos ganan. Ganan los receptores, los transmisores, las localidades, la Universidad, nosotros como historiadores y tal vez gana México como nación, al lograr que un grupo de jóvenes reconozca que su localidad, que la vida sencilla, que los objetos de su casa, que su escuela y que todo en conjunto, son una representación del ser mexicano, aquella ontología que debemos y necesitamos exaltar para que, en el arraigo, se construya una mejor sociedad.

\section{Referencias}

Arias, L.; Casanova, E.; Egea, A.; García, A. A.; Morales, M. (2016). Aprendiendo a tocar la historia. Las fuentes objetuales como recurso de aprendizaje en la educación 
infantil y primaria. En Ciencias sociales, educación y futuro. Investigaciones en didáctica de las ciencias sociales. Libro de actas del simposio (136-148). España, Universidad de Santiago de Compostela.

Bonfil Batalla, G. (1993). Nuestro patrimonio cultural: un laberinto de significados. En Florescano, E. (comp.). El patrimonio cultural de México (19-39). México: Consejo Nacional para la Cultura y las Artes/ Fondo de Cultura Económica.

Burke, P. (1996). Obertura. La nueva historia, su pasado y su futuro. En Burke, P. et al. Formas de hace historia (11-37). Madrid: Alianza.

Carretero M.; Kriger M. (2012). Enseñanza de la historia e identidad nacional a través de las efemérides nacionales. En Carretero, M. y Castorina, J. La construcción del conocimiento histórico. Enseñanza, narración e identidades (56-80). Buenos Aires: Paidós.

Carretero, M. (2007). Documento de identidad. La construcción de la memoria en el mundo actual. Buenos Aires: Paidós.

Cortés Campos, I. (2013). De la selva y las salinas. Historia social de dos pueblosempresa en el oriente de Yucatán (1930-1970). Estudios de Cultura Maya, 42, 119-144.

Domínguez, J.; Arias, L.; Sánchez, R.; Egea, A.; García, F. (2017). Los primeros resultados de una prueba piloto para evaluar el pensamiento histórico de los estudiantes. Clio \& Asociados. La historia enseñada, 24, 38-50.

Dosse, F. (2006). Historia en migajas: de Annales a la "nueva historia". México: Universidad Iberoamericana.

Estepa Giménez, J. (2017). Otra didáctica de la historia para otra escuela. Huelva: Universidad de Huelva.

García Cárcel, R. (1990). Historia de las Mentalidades e inquisición. Chronica Nova, 18, 179-189.

Giménez Montiel, G. (2005). Teoría y análisis de la cultura, vol. 1. México, Consejo Nacional para la Cultura y las Artes.

Ginzburg, C. (1999). El queso y los gusanos. El cosmos según un molinero del siglo XVI. Barcelona: Península.

Gómez Carrasco, C.; Prieto Prieto, J. (2016). Fuentes primarias, objetos y artefactos en la interpretación de la historia. Diseño y evaluación de un taller de numismática en educación secundaria. Didáctica de las ciencias sociales y experimentales, 31, 5-22.

Henderson A.; Levstik, L. (2016). Reading Objects. Children Interpreting Material Culture. Advances in Arqchaeological Practice, 4, 503-516.

Llonch, N.; Molina, E. (2012). Del desván a la escuela. Investigar la educación para la ciudadanía basada en el patrimonio: El aula como museo. En Alba Fernández, N.; García Pérez, F. y Santisteban Fernández, A. Educar para la participación ciudadana en la enseñanza de las ciencias sociales, 2 (27-34). Sevilla: AUPDCS.

Llonch-Molina N.; Parisi-Moreno, V. (2018). Experiencia didáctica para la enseñanza de la historia contemporánea a través de las fuentes en educación superior. Panta Rei. Revista digital de ciencias y didáctica de la historia, 12, 161-176.

Mendo Carmona, C. (1995). Los archivos y la archivística: evolución histórica y actualidad. En Ruiz Rodríguez A. Manual de archivistica (19-38). Barcelona: Síntesis.

Nora, P. (2008). Les lieux de la mémoire. Montevideo: Trilce.

Pagès Blanch, J.; Santisteban Fernández, A. (2010). La enseñanza y el aprendizaje del tiempo histórico en la educación primaria. Cad. Cedes. Campinas, 38(82), 281-309. 
Pagès J.; Plá, S. (2014). Una mirada regional a la investigación en la enseñanza de la historia en América Latina. En Plá, S. y Pagès, J. (coords.), La investigación educativa en la historia de América Latina (13-38). México: Bonilla Artiga/ Universidad Pedagógica Nacional.

Pamuk, O. (2012). The innocence of objects. The Museum of Innocence. Istambul: Abrams/ New York.

Sánchez Estévez, R. (2012). La construcción de los sentidos de la casa y el espacio. Breve recorrido histórico. Especialidades. Revista de Temas Contemporáneos sobre Lugares, Politica y Cultura, 2, 110-128.

Santacana I Mestre, J.; Llonch Molina, N. (2012). Manual de didáctica del objeto en el museo. Gijón: Trea.

Santisteban Fernández, A. (2010). La formación de competencias de pensamiento histórico. Clio \& Asociados. La historia enseñada, 4, 54-56.

Seixas, P. (2017). A Model of Historical Thinking. Educational Philosophy and Theory, 49, 593-605.

Seixas, P.; Peck, C. (2004). Teaching Historical Thinking. In Sears A. \& Wright, I. (Eds.). Challenges and prospect for Canadian Social Studies (109-147). Canada: Pacific Education Press.

Wolf, E. (1994). Europa y la gente sin historia. México: Fondo de Cultura Económica. Zemon Davis, N. (2013). El regreso de Martin Guerre. Madrid: Akal.

\section{Notas}

1 El utillaje mental lo definimos como el conjunto de recursos (categorías conceptuales, filtros emocionales...) que permiten interpretar una realidad objetiva.

2 Este nombre recibió un tipo de sala de madera y petatillo, hecha generalmente con madera de cedro.

3 Remojar la ropa en agua hirviendo junto con productos como la polegía. 